\title{
An Android Based Cooperative Knowledge Acquiring Application
}

\author{
ARIFA BHUTTO*, AND DIL MUHAMMAD AKBAR HUSSAIN* \\ RECEIVED ON 19.02.2018 ACCEPTED ON 25.05.2018
}

\begin{abstract}
The world is tilting more and more towards technology and the use of mobile devices is getting usual day by day. The majority of the user who use these gadgets are younger in age and belong to student class mostly as the mature the age is the learning curve is less responsive; that makes the equipment very evident for the learning. The aim of the proposed application is to promote the positive use of smart phones in the classroom to motivate students towards effective learning, where the goal of learning is achieved through the environment and fellows. By using the inquiry-based learning approach, the application provides a platform for the students to design, share and discuss their own questions with their class fellows. Technology-enabled active learning is a learning format that boosts the factors that affect the overall learning environment. The process starts in between them the eagerness to learn through their own interest and the environment they create amongst their institutes. The android application allows the users to access quiz, forum, view each other's profile, including their statistics and ranking; while the web-based activity management application allows the administrator to manage, monitor, and control different aspects of the system.
\end{abstract}

Key Words: Knowledge Based Systems, Effective Learning Systems, Learning Management Systems.

\section{INTRODUCTION}

1 n old proverb states, "Tell me and I forget, show me and I remember, involve me and I understand." The last part of this statement is the essence of inquiry-based learning. "As traditional way of teaching is more focused on making the students listening and repeating the expected answer to the teacher's questions rather than letting them inquire about the lesson plans per se"; Inquiry based learning is mainly getting involved through questions which leads to understand.
As we know, mobile devices ownership is growing very fast lately; hence, mobile devices can be used to facilitate learning at any place and any time.

In addition, it can support school activities that take place in a context as learning of various elementary subjects like English etc. [1,2]. Laptops have been gradually introduced into educational contexts over the last two decades. Mobile technology has allowed most people to bring their own small computers with

Authors E-Mail: (abh@et.aau.dk,akh@et.aau.dk)

* Department of Energy and Technology, Aalborg University, Denmark.

This is an open access article published by Mehran University Research Journal of Engineering and Technology, Jamshoro under the CC by 4.0 International License. 
outstanding computing capabilities, such as laptops, PDAs (Personal Digital Assistants), PCs (Personal Computers), mobile phones, music players, and electronic books in educational environments [3]. Moreover, during the last few decades, the internet has become a major hub of various services and an approachable communication channel for the world. Its impact can be seen in all the spheres of human life. Its wallops are even visual in the field of education and learning alongside many, peculiarly; world wide web has a great influence in the learning process of students $[3,4]$. The emergence of internet and technologies has made it easier to incorporate the world wide web and many handy software tools in making the learning process of education easy and interesting, where students can not only seek knowledge but it can also help them to enhance their own ability to think and comprehend [3].

Despite the increasing requirement and interest in implementing advance information and communication across the globe, many studies have come out with certain difficulties in incorporation of these technologies in classrooms [3]. By simply placing high level and advance gadget in the classrooms is not the solution. The real problem in implementation is the integration between strategies and technologies.

There have been many attempts to employ technological devices in educational institutes in various countries of the world such as one laptop per child project in Uruguay and Rwanda [5] and prime minister laptop scheme in Pakistan, but; they proved a technological failure according to technological experts as very few of them are used in classrooms [5].

Whereas, many researchers found mobile device employment in the field of education very efficient and useful [5-8]. In the present epoch, mobile devices can not only store but deliver huge amount of curricular data. The fast pace toward technological enhancements in the field of mobile technology - the efficient memory, processing and interconnectivity has made these devices to emerge as the champion of the era [6]. What is more, the mobile devices require less electricity to operate and more functions to offer than the rest of gadgets [7]. Because of this iniquitousness, many students across the globe carry mobile to the educational institutes that may help them in their research works and learning processes in classrooms as well as for interaction with other students [9]. However, a lack of suitable pedagogies can turn these gadgets from blessing to distraction for pupils in a jiffy, especially; when they are required for inquiry-based learning in classrooms [10].

For this purpose, many researchers have worked in the field of promoting inquiry based learning in classrooms through various tools. Primarily, the work was done in the field of web-based and inquiry-based learning [5] as WWW (World Wide Web) has been proved an inception of technology and educational incorporation [3]. For example WISE (Web Inquiry Science Environment) is a web-based inquiry system that is implemented and supported by NSF (National Science Foundation) that provides with various options for sharing, downloading, discussing and criticizing the different scientific issues for students and teachers of almost all the grades [5]. The rapid growth in mobile applications is proved a revolutionary change in the world of technology, which has influenced the learning of students on a larger scale as hundreds of thousands of applications are available on iTunes and Google play stores to pick [11].

As far as educational and learning purposes are concerned there are plenty of systems that provide forum like Yahoo Answers!, Quora, Stack Exchange Communities, and some apps that are focused on quiz like Kahoot, Quiz up and SMILE (Stanford Mobile Inquiry-Based Learning

Mehran University Research Journal of Engineering \& Technology, Volume 37, No. 3, July, 2018 [p-ISSN: 0254-7821, e-ISSN: 2413-7219] 
Environment) [6,12], but they all lack some features that can be essential for learning of students within a class. The most advanced platform that has covered miles in the integration of technology and inquiry based learning approach is SMILE. It is a combination of mobile-based application for students with a management application for teachers or administrator. They can be operated via internet or an ad-hoc local network [6]. Four functions have been deliberately included in the design of SMILE to increase efficiency. First with the SMILE, the flexibility offered by mobile phones, integrates the benefits of multimedia learning [13] by allowing students to ask questions using multimedia elements (for example, photos, video and audio). Secondly, SMILE is designed to support the generation of multiple-choice questions, in which critical thinking students seek alternative distraction options for their questions [4,14]. Fourth, the feedback system through rating by users generate a sense of non-feedback system through rating by users generate a sense of non-pressurized competition which helps in motivating students to enhance their understanding and learning skills [15]. To sum up all, the SMILE project uses mobile technology as a learning tool to support an interactive learning environment centred on the student and to help students generate and share questions related to what they have learned. These can help improve the learning process for students by giving them the opportunity to reflect on classroom materials and use what they have learned to formulate personally relevant questions. The characteristic of sharing questions allows students to deepen their knowledge by acquiring concepts that can ignore or clarify concepts that can be misinterpreted by solving peer questions [7].

However, these come with its shortcomings; those are used on a wireless local network within a classroom. The students cannot participate anytime they want. In SMILE the test has to be started by the teacher. In addition, it does not provide any feature to ask questions for discussion. Hence, the proposed system is a step ahead from all its heralds, it also cost effect system.

The system that would enable students to quickly create multiple choice questions and share them with their classmates using mobile phones anytime with responding feature to rate each other's questions and to view detailed question related data (including who has the most number of points, ranks etc.). The project is a combination of two applications, an android-based application to be used by the students, and a webbased application for the teacher or administrator. Furthermore, the android application consists of two main modules: the quiz module and the forum module. The quiz module allows the users to create their own multiple-choice questions by providing the question, its four possible answer, an image to better understand, the question and the correct answer among the four options. The students can also answer and rate multiple-choice questions that were created by other classmates. Whereas, in the forum module students can create a question that needs a descriptive answer. They can also answer questions created by their classmates and vote up or vote down them depending on the relevance or accuracy of the answer. The answers are of a questions are ordered by the rank of the answer that is determined by an algorithm. Thus, it offers better services as compared to all of its predecessor technologies.

\section{ANALYSIS AND DESIGN}

The methodology of this study has been designed on the process model of RAD (Rapid Application Development) model because it provides a parallel and systematic development of functions and components. By following the RAD approach, we used different off-the-shelf components and some components from our past projects to save the time. In addition, the functions were developed in an incremental way and by individuals. Fig.1 RAD methodology is define, each cycle following the linear sequential way of development process, but it is quick

Mehran University Research Journal of Engineering \& Technology, Volume 37, No. 3, July, 2018 [p-ISSN: 0254-7821, e-ISSN: 2413-7219] 
and fast because each cycle show demo of the product on basis of the demo next level or cycle start.

As this is an android-based application, the student uses the android application. One can create a question or quiz or forum, view questions created by other students of his/her class, answer those questions, view result, vote up $(+1)$ or vote down $(-1)$, the answers in forum, report inappropriate questions and answers, view profiles of other students and view list of students who has got the most number of points as reward.

The administrator will use the activity management application as shown in Fig. 2 to manage the overall system and activities. The administrator can view overall statistics like top scorers, highest rated questions, and user statistics, manage (create, view, update, delete) batches, classes, subjects, quiz questions, forum questions, and the users including the validation of newly registered users shows in Fig 2. Use case diagram for the overall system for the Android Application is shown in Figs. 3-4, respectively.

The architectural diagram of the system in Fig. 5 shows the high-level design of the system. The android application cannot directly communicate with the external database server on the internet, thus the RESTful API (Application Programming Interface) was used to directly communicate with the database server by passing the information in JSON (JavaScript Object Notation) format with HTTP (The Hypertext Transfer Protocol) POST/GET Requests.

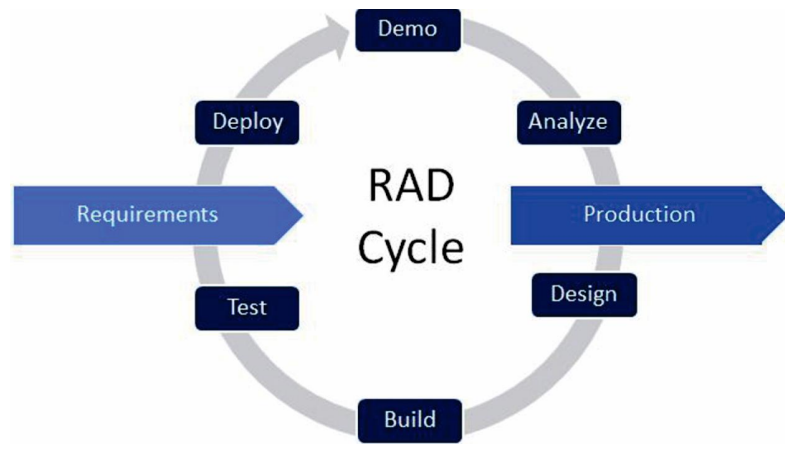

FIG. 1. RAD METHODOLOGY OF DEVELOPMENT
On the other hand, the web-based [11] activity management application does not require any intermediate and can directly connect to the database server on the internet.

The activity diagram in Fig. 6 shows in principle, the flow from one activity to another. In our system, the start of the activity needs as the first action, to register your account; login to the system, create a project, add members to the project and manage the system. In case if the user has already been added to the project, it immediately starts using the project. One can use the system functions in parallel if the user wants to continue using the system features, otherwise; the user can disconnect from the system and terminate the activity.

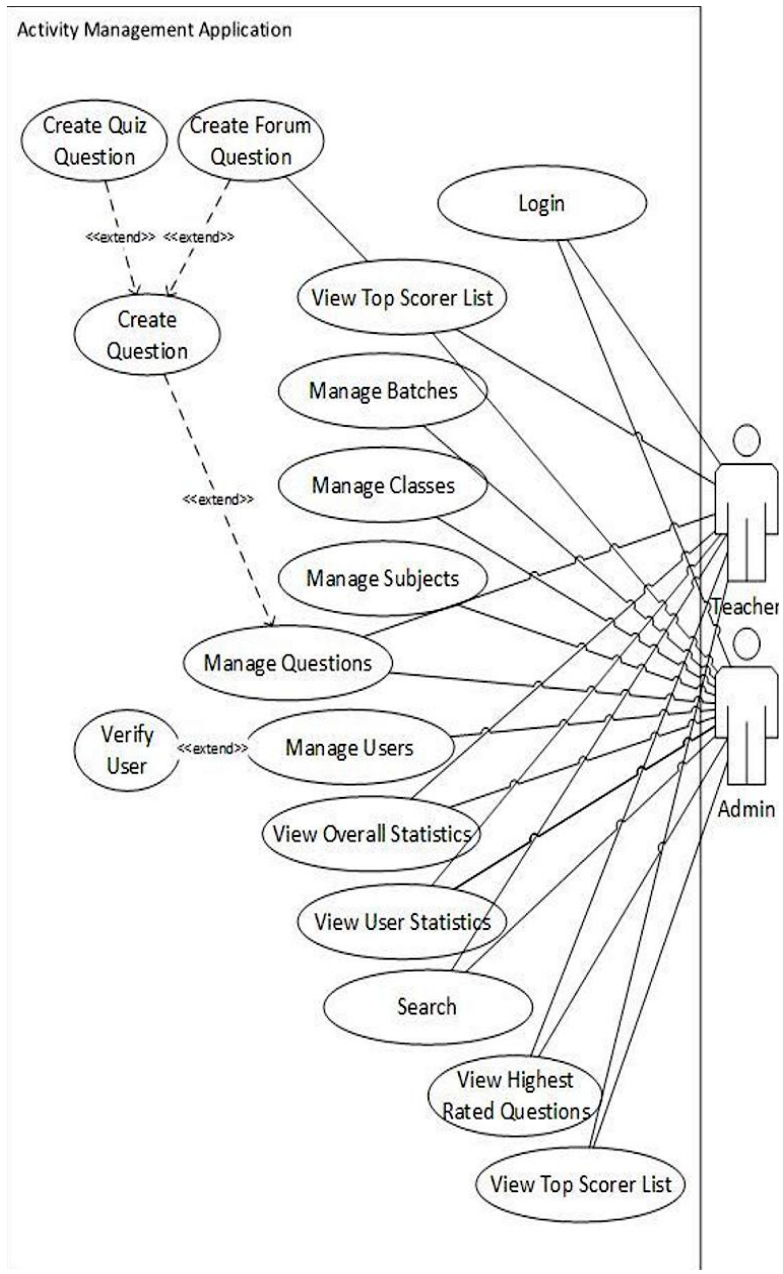

FIG. 2. USE-CASE DIAGRAM FOR ACTIVITY MANAGEMENT APPLICATION (ADMINISTRATOR)

Mehran University Research Journal of Engineering \& Technology, Volume 37, No. 3, July, 2018 [p-ISSN: 0254-7821, e-ISSN: 2413-7219] 


\section{RESULTS}

It is an android-based application therefore, it has been tested on different devices with different versions of operating systems and APIs. Initially, we tested it as a unit, which follows its integration in the system.

The rating of the questions in the quiz simply works by finding the average rating between the new rating (provided by the student who just rated the question) and the one already stored in the database.

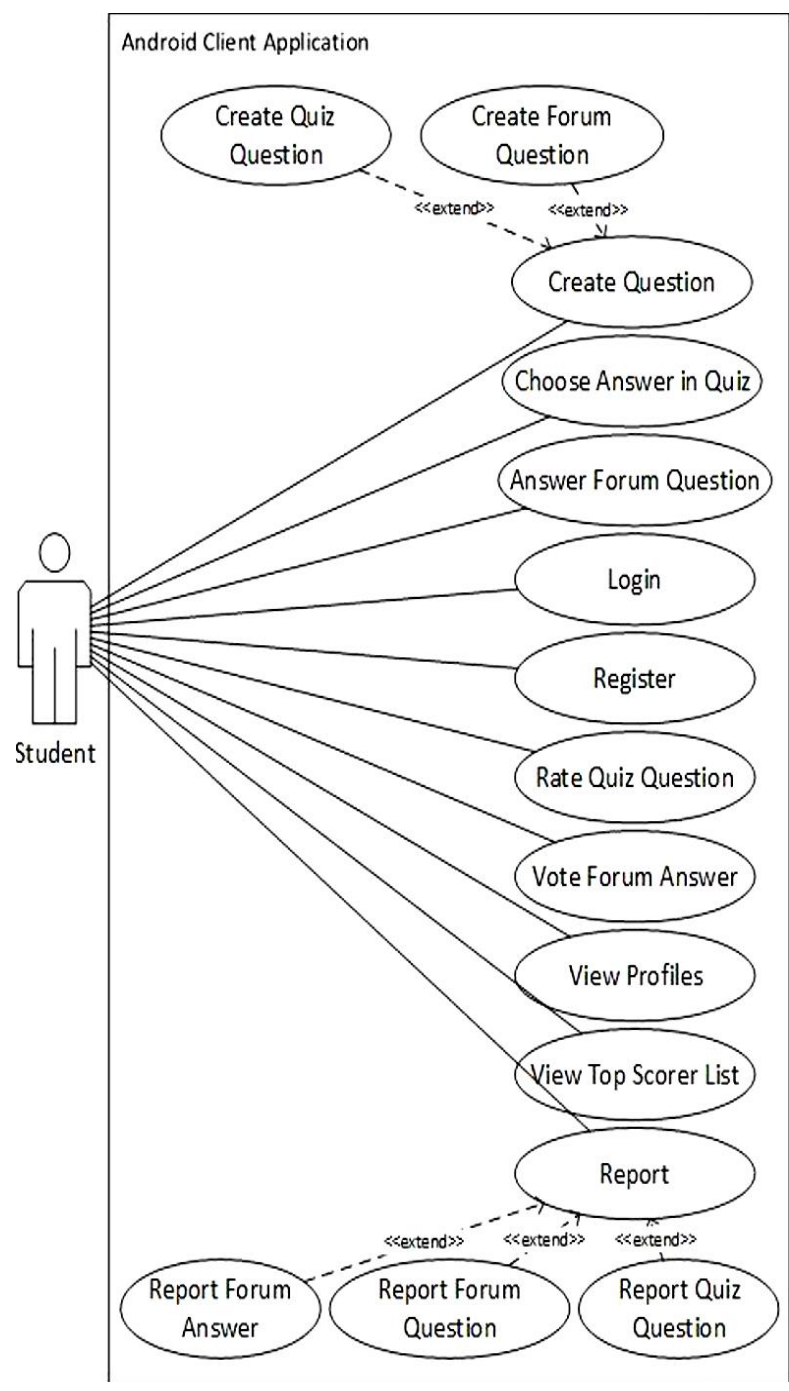

FIG. 3. USE-CASE DIAGRAM OF ANDROID APPLICATION (STUDENT)
New Rating $=($ Current Rating + Old Rating $) / 2$

Where, new Rating is the new rating of the question that is going to be considered, current Rating is the rating provided by the student, and old Rating is the previous average rating already stored in the database.

The order of answers on a question in forum plays an important role. It shows the relevance, accuracy and the quality of the answer. In the system, the answers are ordered by a rank. The rank is generated by counting both the up votes and the down votes received on the answer.

Below is the formula that is used to find the rank of an answer:

Rank $=$ Number of Up Votes - Number of Down Votes

Then the results are shown in Table 1, describing the various formation of the test results. Like in Table.1, results shown for the Answer-B got the highest rank because it got less negative votes among all answers.

Same in case of lowest ranking, Answer-A received lowest ranked, because it posted longer time and receiving more negative votes which affect the ranking results.

However, the results of the systems meet up to the required expectation on basis of getting higher and lower ranking according the voting parameter and second we found the time also secondary criteria.

The system is able to work on all platforms as well as with all sizes of screen and it fulfils all the requirements and specifications. 


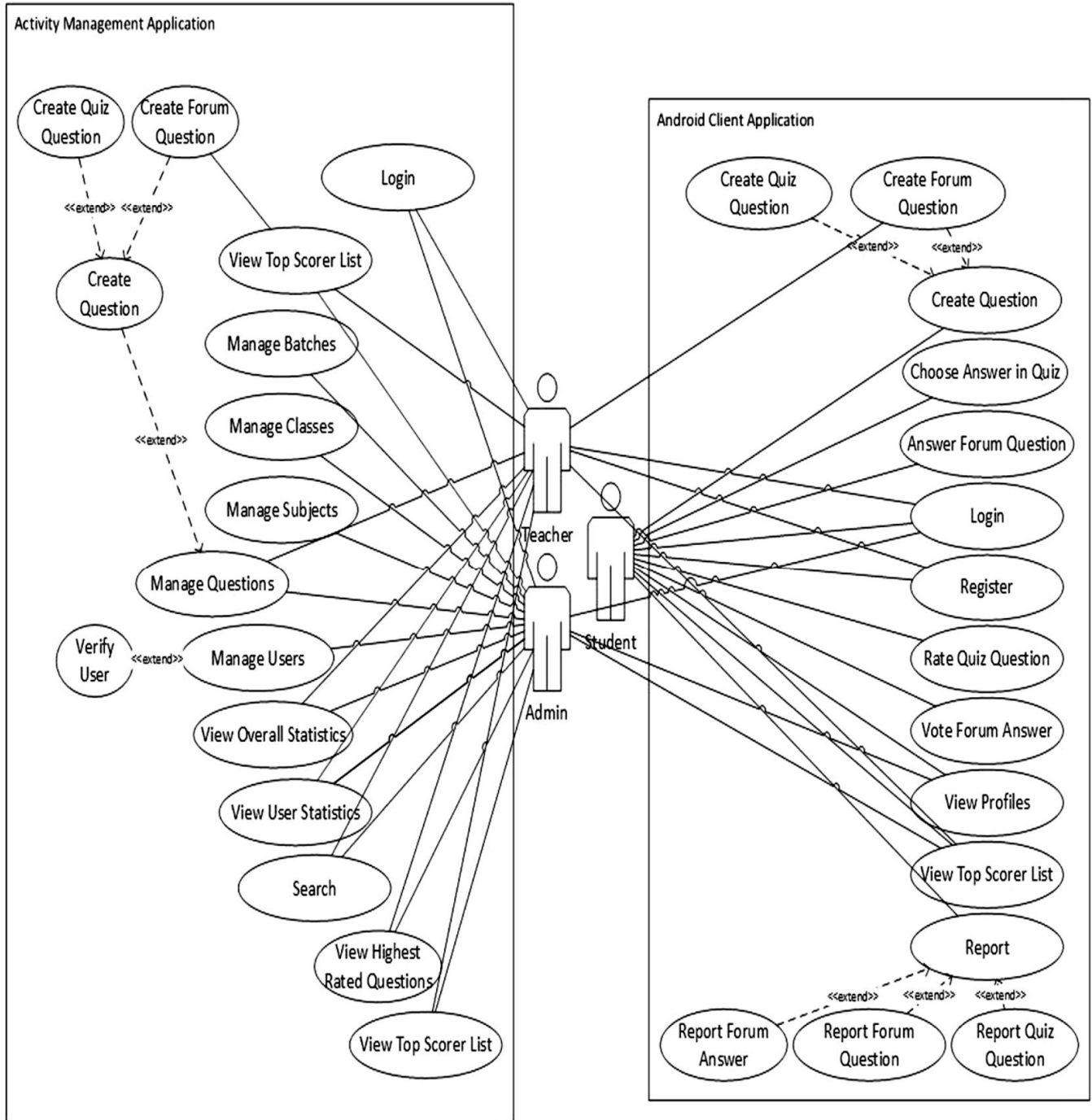

FIG. 4. USE-CASE DIAGRAM FOR OVERALL SYSTEM

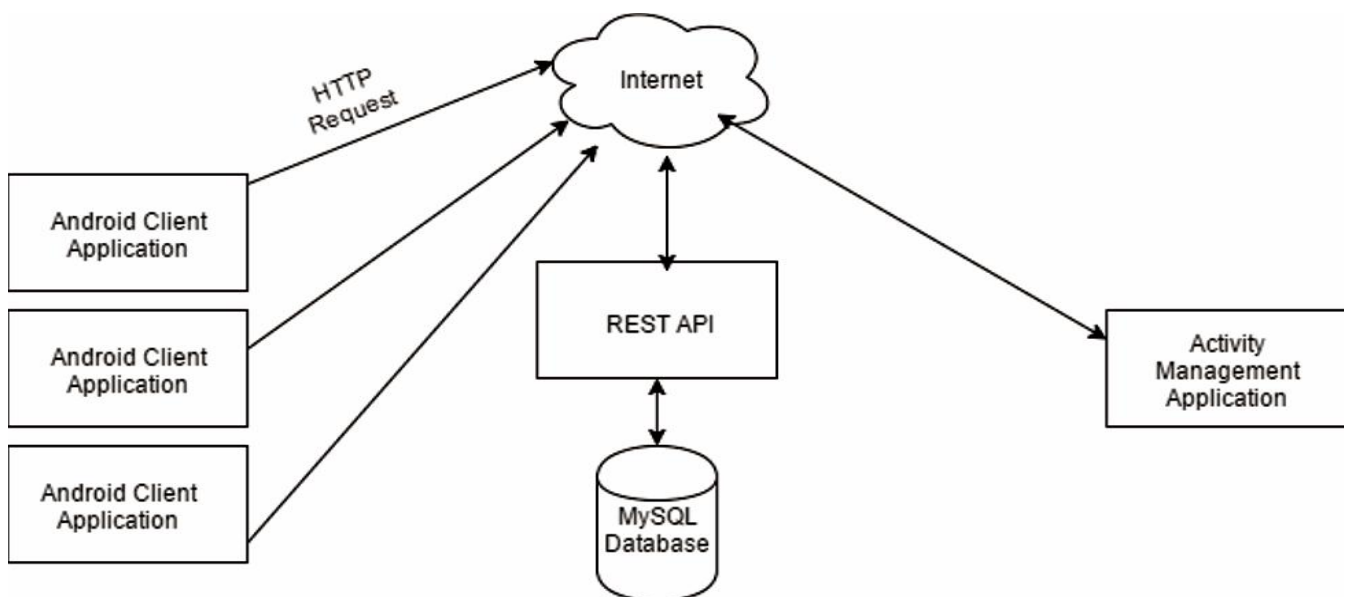

FIG. 5. SYSTEM ARCHITECTURE DIAGRAM

Mehran University Research Journal of Engineering \& Technology, Volume 37, No. 3, July, 2018 [p-ISSN: 0254-7821, e-ISSN: 2413-7219] 


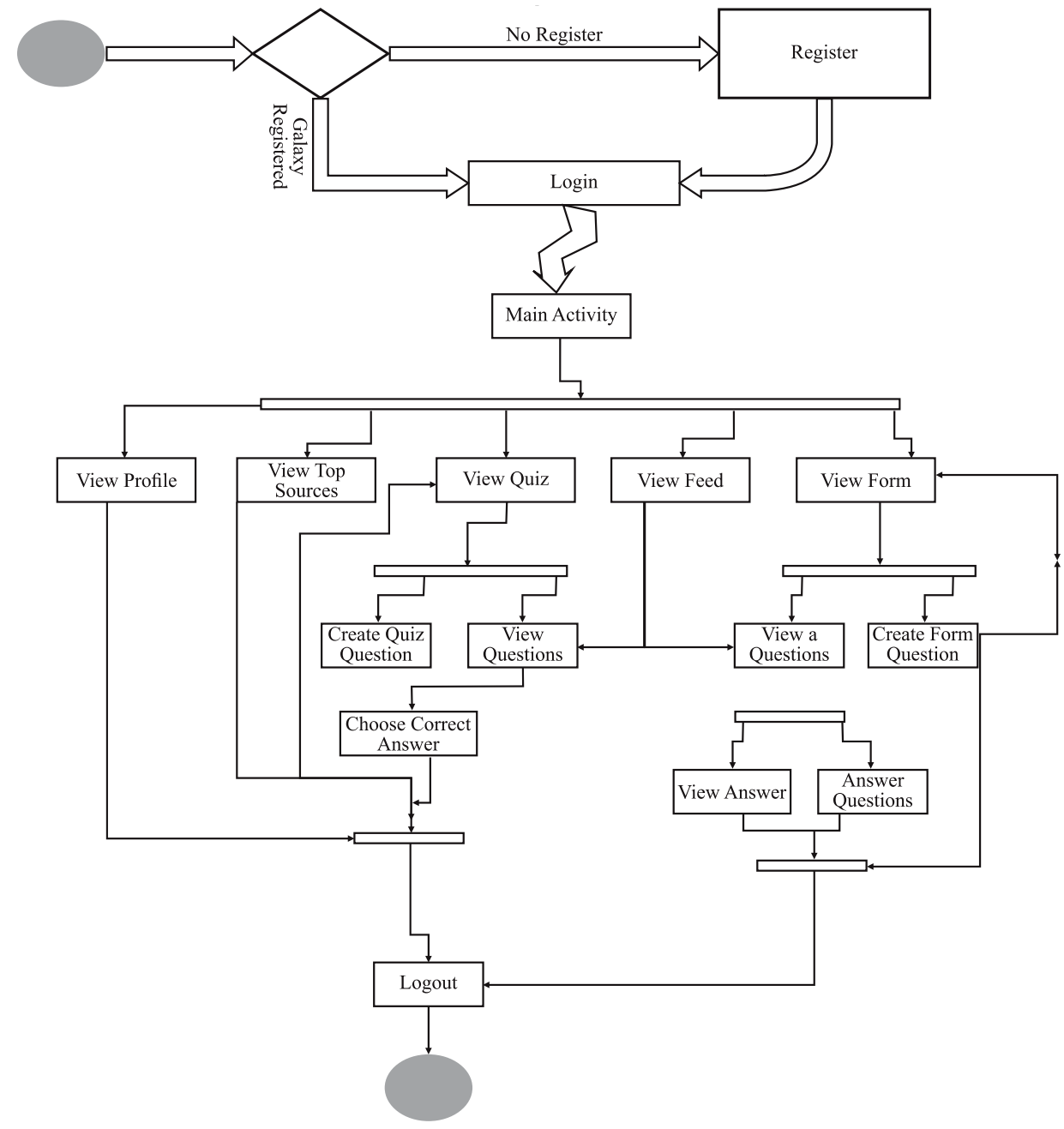

FIG. 6. ACTIVITY DIAGRAM

TABLE 1. RANKING FOR COOPERATIVE KNOWLEDGE ACQUIRING APPLICATION

\begin{tabular}{|c|c|c|c|c|}
\hline Answer & Votes & Rank & Order & Time \\
\hline Answer A & $\begin{array}{c}20 \text { up votes } \\
30 \text { down votes }\end{array}$ & -10 & 4 & Posted 2 days ago \\
\hline Answer B & $\begin{array}{c}10 \text { up votes } \\
1 \text { down vote }\end{array}$ & 9 & 1 & Posted 5 hours ago \\
\hline Answer C & $\begin{array}{c}2 \text { up votes } \\
\text { down votes }\end{array}$ & -3 & 3 & Posted 1 hour ago \\
\hline Answer D & 6 down votes & 6 & 2 & Posted 10 minutes ago \\
\hline
\end{tabular}

\section{CONCLUSION}

The research provides students of the same grades to ask questions and share their ideas with one another. This study gives them a platform for a healthy competition where their cognizing abilities might grow and their learning skills can be enhanced largely specially for the students who are too shy to participate and ask questions in the classroom environment. Through this research, teachers can have a good understanding toward the

Mehran University Research Journal of Engineering \& Technology, Volume 37, No. 3, July, 2018 [p-ISSN: 0254-7821, e-ISSN: 2413-7219] 
mental capabilities of the students. By implementing this system in classroom, the educational pedagogies might be lifted up to the higher levels of the effective learning.

There are number of features those could be added in the future work to improve the results, the ranking of answers could be integrated by changing the methods to include other factors like time, and expertise of the user; who is answering. The expertise of a student can be determined and automatically updated by the ratio of the correct and incorrect answers in the quiz, and number of positive votes about his/her answers they receive regarding a subject. The Push-notification for a subscribed question or subject would make it easy to keep track of the activities in the forum.

\section{ACKNOWLEDGEMENT}

This research work was conducted and supported by the Department of Energy \& Technology, Aalborg University, Denmark. Authors greatly acknowledge and appreciate their excellent unconditional support for using laboratories and other facilities. Special thanks to Jens Bo, Head of Section, Esbjerg Campus, for his constant involvement in keeping the status updated with short seminar/presentations.

\section{REFERENCES}

[1] Temple, C.A., Ogle, D., Crawford, A., and Freppon, P.A., "All Children Read: Teaching for Literacy in Today's Diverse Classrooms", Pearson, 2018.

Homer, R., Hew, K.F., and Tan, C.Y.,"Comparing Digital Badges-and-Points with Classroom Token Systems, Effects on Elementary School ESL Students' Classroom Behavior and English Learning", Journal of Educational Technology \& Society, Volume 21, No. 1, pp. $137-151,2018$.

[3] Schweisfurth, M., "Learner-Centred Education In Developing Country Contexts: From Solution To Problem?", International Journal of Educational Development, Volume 31, No. 5, pp. 419-426, [DOI: 10.1016/j.ijedudev.2011.04.009], 2011.

[4] Birenbaum, M., and Dochy, F. "Alternatives in Assessment of Achievements, Learning Processes and Prior Knowledge", Springer Science \& Business Media, Volume 42, 2012.
Traxler, J., "Current State of Mobile Learning", Mobile Learning Transforming the Delivery of Education and Training, Volume 5, No. 2, [https://www.academia.edu/ 180449/Current_State_of_Mobile_Learning], 2009.

[6] Kim, P., Hagashi, T., Carillo, L., Gonzales, I., Makany, T., Lee, B., and Gàrate, A. "Socioeconomic Strata, Mobile Technology, and Education: A Comparative Analysis, Educational Technology Research and Development, Volume 59, No. 4, pp. 465-486, [DOI: 10.1007/s11423-010-9172-3], 2011.

[7] Pietrzyk, C., Semich, G., Graham, J., and Cellante, D., "Mobile Technology in Education", Society for Information Technology \& Teacher Education International Conference, pp. 640-650, 2011.

[8] Kim, P., and Chiang, Y.V., "Using Mobile Phones To Scaffold Student-Generated Questions And Promote A Global Student-Centered Mobile Interactive Learning Environment (SMILE)", Society for Information Technology \& Teacher Education International Conference, Association for the Advancement of Computing in Education, pp. 3462-3465, 2012.

[9] Shuler, C., Levine, Z., and Ree, J., "iLearn II an Analysis of the Education Category of Apple App Store", The Joan Ganz Cooney Center Sesame Workshop, January, 2012 .

[10] Kim, D.W., "A Web-Based Learning Support System for Inquiry-Based Learning Using Treasure Hunt", M.Sc. Thesis, Faculty of Graduate Studies and Research, University of Regina, December, 2009.

[11] Slotta, J.D., and Linn, M.C., "WISE Science: Web-Based Inquiry in the Classroom", Teachers College Press, 2009.

[12] Zhou, Y., and Yao, J.T., "A Web-Based Learning Support System for Rough Sets", International Conference on Rough Sets on Knowladge Technology, pp. 161-162, [DOI: 10.1007/978-3-319-11740-9], Springer, 2014.

[13] Thornton, P., and Houser, C., "Using Mobile Phones In English Education In Japan", Journal of Computer Assisted Learning, Volume 21, No. 3, pp. 217-228, 2005.

[14] Mayer, R.E., "Multimedia Learning: Are We Asking The Right Questions?", Educational Psychologist, Volume 32, No.1, pp. 1-19, 1997.

[15] Lee, H.-S., Liu, O.L., and Linn, M.C., "Validating Measurement of Knowledge Integration in Science Using Multiple-Choice And Explanation Items", Applied Measurement in Education, Volume 24, No. 2, pp. 115-136, 2011. 